\title{
Neurodevelopmental Outcomes According to Brain Injury Patterns in Neonates with Postasphyxial Hypoxic Ischemic Encephalopathy
}

\author{
Seung Yeon Jeong, M.D., Seo Yeol Choi, M.D., Young Pyo Chang, M.D., and Young Seok Lee, M.D.* \\ Departments of Pediatrics and Radiology*, Dankook University College of Medicine, Cheonan, Korea
}

\section{ABSTRACT}

Purpose: To investigate the relationship between brain injury patterns on magnetic resonance imaging (MRI) and neurodevelopmental outcomes in neonates with postasphyxial hypoxic ischemic encephalopathy (HIE).

Methods: Clinical characteristics and brain MRI findings of 49 term neonates with postasphyxial HIE were retrospectively reviewed. Brain injury patterns in MRI were classified into five categories, along with evaluation of the posterior limb of internal capsule (PLIC). Neurodevelopmental outcomes were assessed by neurological examination combined with the Bayley Scales of Infant Development II between 1 and 2 years of age.

Results: Twenty-three neonates (46.9\%) showed abnormal brain MRI finding associated with poor neurodevelopmental outcomes (odds ratio 9.7, 95\% confidence interval 1.4, 67.4, $P=0.022)$. The following injury patterns were seen in MRI: abnormality in the basal ganglia-thalamus (BGT) in 4 neonates (17.4\%), watershed predominant (WP) pattern in 5 (21.7\%), extensive global injury (EGI) in $3(13.0 \%)$, lesions restricted to periventricular white matter (LPWM) in 4 (17.4\%), and perinatal arterial ischemic stroke (PAIS) in 2 (8.7\%). Additionally, 6 neonate $(26.1 \%)$ showed lesion in the PLIC. Neonate with BGT and EGI injury patterns showed worse neurodevelopmental outcomes than those with WP and LPWM patterns $(P<0.05)$. Neonate with PLIC lesion also showed poor outcomes (100\%).

Conclusion: Abnormal brain MRI findings in neonates with postasphyxial HIE were associated with the poor neurodevelopmental outcomes. BGT, EGI and PLIC patterns of injury are expected to have worse outcomes than white matter predominant injury patterns such as those in the WP and LPWM.

Key words: Neonatal hypoxic ischemic encephalopathy, Brain injury, Brain magnetic resonance imaging, Neurodevelopmental outcome
Received: 3 August 2016

Revised: 25 October 2016

Accepted: 28 October 2016

Correspondence to: Young Pyo

Chang

Department of Pediatrics, Dankook University College of Medicine 201, Manghyang-ro, Dongnam-gu, Cheonan 31116, Korea

Tel: +82-41-550-3937

Fax: +82-41-556-0524

E-mail: ychang@dankook.ac.kr

Copyright(c)

By Korean Society of Neonatology.

All right reserved.

This is an Open-Access article distributed under the terms of the Creative Commons Attribution Non-Commercial License (http://creativecommons.org/licenses/ by-nc/4.0), which permits unrestricted non-commercial use, distribution, and reproduction in any medium, provided the original work is properly cited. 
서론

신생아 가사로 인한 저산소 허혈 뇌병증(hypoxic ischemic encephalopathy)은 신경 발달 장애와 신생아 사망의 주요 원인 이다. 신생아 1,000명 당 2-5명이 주산기에 뇌 손상을 받으며, 생 존아의 20-40\%가 신경학적 후유증과 신경 발달 장애를 가진다 ${ }^{1)}$. 최근에 고위험 신생아의 생존이 증가함에 따라 생존아에 대한 신경 발달 장애의 조기 진단과 조기 치료의 중요성이 점차 증가하 고 있다. 저산소 허혈 뇌병증 환자의 신경학적 예후를 예측하는 데 에는 임상적 소견이 가장 중요한 것으로 알려져 있으나 그 외에 예 후 예측을 위한 객관적인 검사가 시행되고 있다 ${ }^{2-4}$. 신경학적 예후 예측에 사용되는 검사에는 뇌파(electroencephalography, EEG), 뇌 자기 공명 촬영(magnetic resonance imaging, MRI), 뇌 초 음파(brain ultrasonography), 감각 유발 전위(sensory evoked potential, SEP), 시각 유발 전위(visual evoked potential, VEP) 등 이 이용되고 있다 ${ }^{5}$. 이 중 영상학적 검사로서 뇌 초음파와 뇌 MRI 는 저산소 허혈 뇌병증의 병태 생리 이해와 예후 예측에 가장 널리 이용되고 있는 검사인데 뇌 초음파의 경우 신경학적 예후를 예측 함에 있어 MRI에 비하여 정확도가 떨어져 있는 것으로 알려져 있 으며, 뇌 손상을 확진하기 위해서는 MRI가 필요한 경우가 많다 5 ,6)

저산소 허혈 뇌병증의 뇌 MRI 소견은 다양한 형태를 보인다.,8) 또한, 뇌 손상 형태에 따라 주산기 저산소 허혈 뇌병증의 발생 위 험 인자와 뇌신경 발달의 예후에 차이를 보인다,10). 이에 관련하 여, de Vries와 Groenendaal ${ }^{11}$ 은 신생아 저산소 허혈 뇌병증의 뇌 MRI에서 뇌 손상 병변의 형태를 분류하고 이에 따라 신경 발달 예후에 차이가 날 수 있음을 제시한 바 있다. 그러나 뇌 MRI 병변 형태에 따른 신생아 저산소 허혈 뇌병증의 신경 발달 예후의 차이 에 대한 연구는 최근까지도 제한적이다 ${ }^{12-16)}$. 이에 연구자들은 가
사 후 신생아 저산소 허혈 뇌병증 환자의 뇌 MRI를 이용하여 de Vries와 Groenendaal ${ }^{11}$ 의 분류에 근거하여 뇌 손상의 형태를 분 류하고 신경 발달 예후를 알아보고자 하였다.

\section{대상 및 방법}

\section{1. 대상}

본 연구는 단국대학교병원 기관생명윤리 위원회의 승인을 받았 다(DKUHIRB 2016-08-001). 2005년 1월부터 2014년 12월까지 단국대학교 부속 병원 신생아 집중치료실에서 주산기 가사로 인 한 저산소 허혈 뇌병증으로 입원 치료하였던 재태 기간 36 주 이상 인 신생아 84명 중 주요 선천성 기형 및 염색체 이상, 선천성 대사 이상, 선천 감염의 증거가 있었던 환자 25 명과 입원 중 MRI 촬영 을 못했거나 사망한 환자 10명을 제외한 49 명을 대상으로 하였다.

주산기 가사로 인한 신생아 저산소 허혈 뇌병증의 진단 기준 은 출생 후 불안, 기면, 혼수 등의 의식의 변화와 경련, 무호흡 등 의 명백한 뇌증이 있으면서 출생 후 5분 Apgar 점수가 7 미만, 분 만 중 신생아에 위험을 초래하는 주요 사건(intrapartum sentinel events), 신생아 집중 치료실 입원 후 1 시간 이내에 시행한 동맥혈 가스 분석에서 심각한 대사성 산증( $\mathrm{pH}<7.1$ or base excess $>15$ $\mathrm{mmol} / \mathrm{L})$, 출생 시 기계적 환기 요법의 필요들 중에 하나 이상이 있는 경우로 하였다 ${ }^{3,17-21)}$.

\section{2. 뇌 MRI 촬영}

뇌 MRI는 1.5 Tesla General Electric Signa System (GE Medical System, Milwaukee, WI, USA)으로 시행하였고, 가로면 (axial)의 T1-가중영상(T1-weighted conventional spin echo image; $4 \mathrm{~mm}$ thickness, repetition time $500 \mathrm{~ms}$, echo time

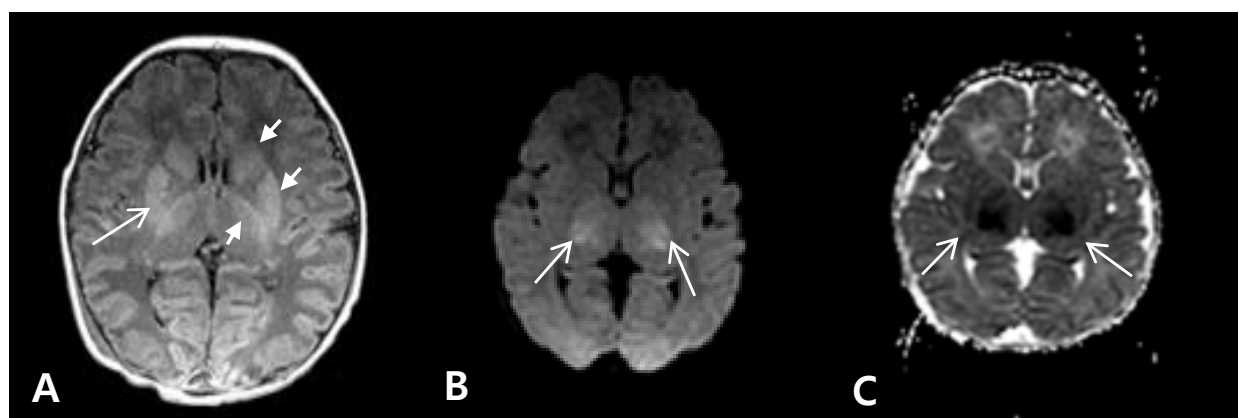

Figure 1. Basal ganglia-thalamus pattern (BGT) in infant born at 38+6 weeks, delivered by emergency cesarean section due to fetal distress and showed seizure on day 1 . Brain MRI was performed on day 3. (A) T1-weighted image shows high signal intensity in the caudate nucleus (upper short arrow), lentiform nucleus (middle short arrow) and thalamus (low short arrow). There is absence of a normal signal within the posterior limb of the internal capsule (long arrow). (B) DWI shows bilateral restricted diffusion with the increased signal intensity in the thalamus and lentiform nucleus (arrows). (C) ADC map shows the bilateral low signal intensity in the thalamus and lentiform nucleus (arrows). 
$11 \mathrm{~ms})$, T2-가중영상(T2-weighted fast spin echo image; 4 $\mathrm{mm}$ thickness, repetition time $3000 \mathrm{~ms}$, echo time 60 and $\mathrm{ms})$, fluid attenuated inversion recovery (FLAIR), diffusion weighted Imaging (DWI), apparent diffusion coefficient $(\mathrm{ADC})$ 를 관찰하였다 ${ }^{22)}$. 모든 대상아는 출생 3일에서 21일 사이에 뇌 MRI가 촬영되었으며 촬영된 영상은 한 명의 소아 영상의학과 전문의와 뇌 MRI 판독에 익숙한 또 다른 한 명의 영상의학과 전문 의에 의하여 재 판독되었다.

\section{3. 뇌 MRI 소견의 분류}

주산기 저산소 허혈 뇌병증의 뇌 MRI 소견은 de Vries와 Groenendaal $^{11)}$ 의 분류를 기준으로 주로 5 가지 형태로 분류하였다. 첫째로, 중심 회백질 핵(central gray nuclei)과 롤란드주변부 겉 질(perirolandic cortex)에 주로 병변이 나타나는 basal gangliathalamus predominant pattern (BGT) (Figure 1), 둘째로, an-

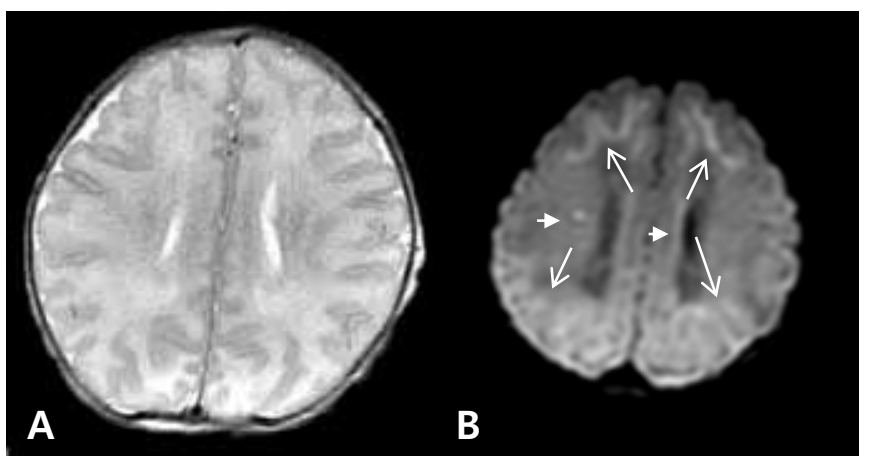

Figure 2. Watershed predominant pattern (WP) in Infant born at $37+6$ weeks with meconicum aspiration. Brain MRI was performed on day 3. (A) T2-weighted image does not show the significant abnormality. (B) But, DWI shows restricted linear high signal intensities in both frontal and temporoparietal subcortical areas with overlying cortex (long arrows). There is also involvement of the periventricular white matter (short arrows). terior-middle cerebral artery 와 posterior-middle cerebral artery의 경계 부위인 뇌혈관 분수계(watershed zone)의 겉질 밑 백질과 그 주변부 겉질을 침범하는 것이 주 병변인 watershed predominant pattern (WP) (Figure 2), 셋째로, 병변이 대뇌의 겉 질밑 백질과 겉질에 전반적으로 나타나면서 상대적으로 소뇌, 뇌실 주변부 백질, 뇌 중심부 회백질 등은 비교적 보존하여 white cerebrum을 보이는 extensive global injury pattern (EGI) (Figure 3), 넷째로, 병변이 뇌실 주변부 백질에 국한된 lesion restricted to periventricular white matter (LPWM) (Figure 4), 다섯 번째로는 주산기 동맥혈 허혈에 의한 출혈성 또는 비출혈성 병변(perinatal arterial ischemic stroke, PAIS)으로 분류하였다(Figure 5). 본 연 구에서는 위 다섯 가지 소견 외에 신경학적 예후가 매우 불량한 것 으로 알려진 posterior limb of internal capsule (PLIC)을 침범한 경우를 여섯 번째로 추가 분류 관찰하였다 ${ }^{23)}$.

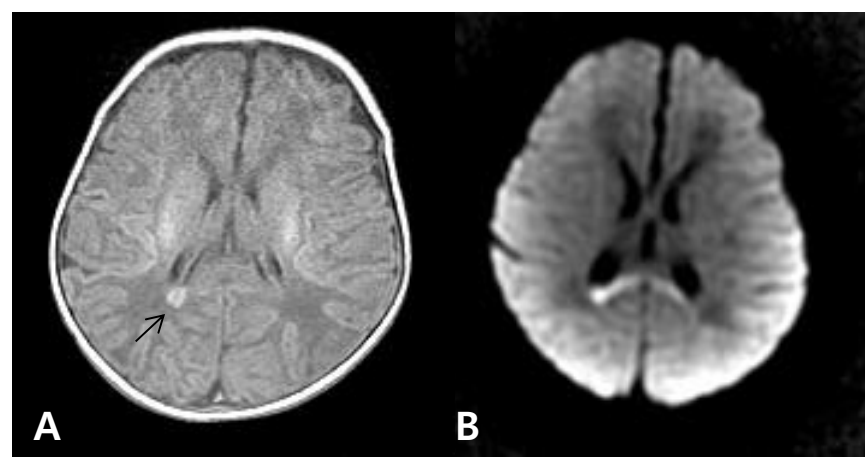

Figure 4. Lesion restricted to the periventricular white matter (LPWM) in infant born at $40+0$ weeks with placenta abruption. MR performed on day 7. (A) T1-weighted image shows punctuated focal lesion with high signal intensity in right perigonal white matter (arrow). (B) There is restricted lesion also seen in the splenium of corpus callosum on DWI.

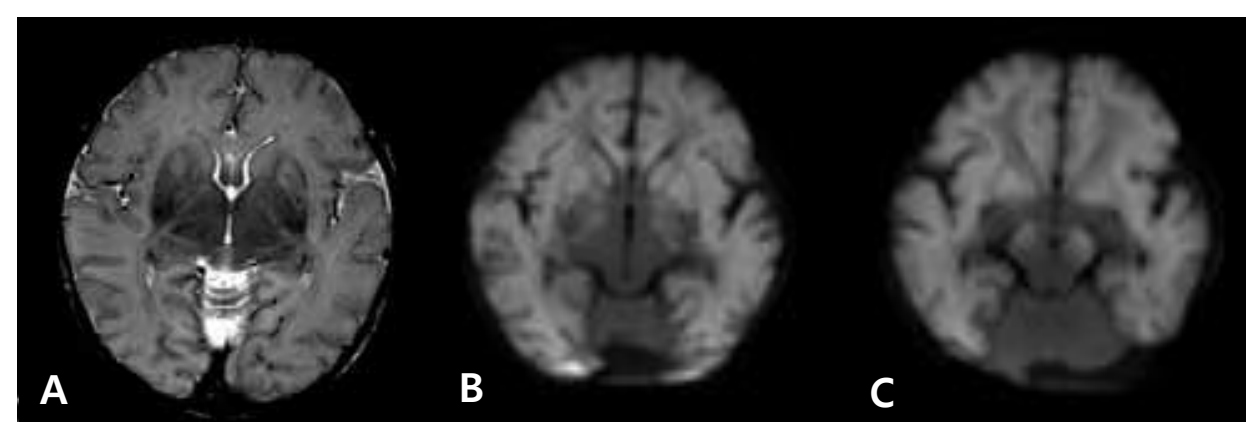

Figure 3. Extensive global injury pattern (EGI) in infant born at 38+4 weeks, delivered by emergency cesarean section due to placenta abruption. Brain MRI was performed on day 7. (A) T2-weighted image shows diffuse increased signal intensity in the subcortical white matter and the cortex of the whole cerebrum. There is a relative sparing of the basal ganglia and immediate periventricular white matter. (B, C) DWIs confirm the 'white cerebrum' with the restricted diffusion in the whole cerebrum and the relative sparing of the brain stem and the cerebellum. 


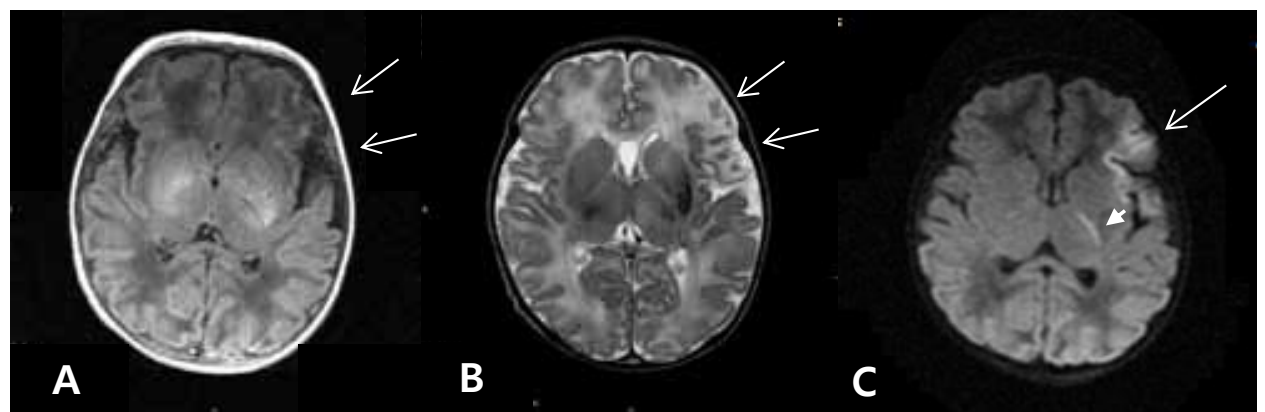

Figure 5. Perinatal arterial ischemic stroke in infant born at 40+1 weeks, delivered by emergency cesarean section due to fetal distress. MR performed on day 8. (A, B) Focal low and high signal intensities are seen in the fontoparietotemporal area on T1- and T2-weighted images, respectively. These findings suggest the infarct of the left middle cerebral artery territory (long arrows). (C) Restricted diffusion is seen in the frontoparietotemporal cortex and subcortical area on DWI (long arrow). There is restricted diffusion also seen in the posterior limb of internal capsule (short arrow).

\section{4. 대상아의 임상 소견}

대상아들의 임상 소견은 의무 기록을 후향적으로 분석하였으 며 재태 기간, 출생체중, 성별, 1 분과 5 분 Apgar 점수, 신생아 저산 소 허혈 뇌병증 중증도, 분만 중 태아의 뇌 손상을 유발할 수 있는 주요 위험 사건(intrapartum sentinel events), 신생아 주요 질환 (태변 흡인, 신생아 호흡 곤란 증후군, 지속성 폐동맥 고혈압증, 급 성 신부전, 경련 등), 혈액가스 분석 소견, 신생아 소생술 시행 여부, 그 외에 주산기 또는 분만과 연관된 주요 요인들, 출생 후 치료로 혈압 강화제 사용, 인공호흡기 사용, 저체온 치료 등이 포함되었다.

\section{5. 뇌 신경발달 평가}

출생 후 1 세에서 2 세 사이에 시행한 Bayley 발달 검사 II와 신경 학적 진찰로 뇌신경 발달의 이상을 판단하였다. Bayley 발달 검사 는 지능 발달 지수(mental developmental index, MDI)와 운동 발 달 지수(psychomotor developmental index, PDI)로 평가하였 으며 MDI 또는 PDI가 70 미만인 경우를 의미 있는 발달 지연으로 정의하였다. 뇌성 마비는 사지 중 어느 하나가 비진행형인 경직성 (spastic) 또는 근이상성(dystonic) 근육 수축 또는 자세 유지 장 애 및 운동 장애가 있는 경우로 하였다. 또한 퇴원 전 뇌간유발반응 청력검사(brain evoked response audiometry)를 시행하고 이상 이 있는 경우 생후 6개월까지 2-3회 추가로 실시 후 지속적인 이상 이 있을 때 감각신경성 난청으로 진단하였다. 발달 지연, 뇌성마비 와 감각신경성 난청 중 하나 이상 있으면 나쁜 뇌 신경 발달(poor neurodevelopmental outcome)을 가지는 것으로 정의하였다.

\section{6. 통계 분석}

통계 분석은 SPSS version 23.0 (IBM Co., Armonk, NY, USA) 통계 프로그램을 이용하였다. 대상아의 임상 소견과 뇌 신경 발달 평가 소견을 정상 $\mathrm{MRI}$ 소견을 가지는 그룹과 비정상 $\mathrm{MRI}$ 소견을 가지는 그룹으로 나누어 Chi square test, Student $t$-test, Fisher's exact test로 분석하였으며 나쁜 뇌 신경 발달 예후와 관계있는 독 립인자를 로지스틱 회귀분석(logistic regression analysis)으로 조정하여 분석하였다. 비정상 MRI 소견을 뇌 손상 형태에 따라 분 류하고 이 분류에 따른 뇌 신경 발달 예후의 차이를 분석하였다. 통계적 유의 수준은 $P<0.05$ 로 하였다.

\section{결과}

\section{1. 대상아의 임상적 특징}

대상아 49 명의 평균 출생체중은 $3,171.3 \pm 647.8 \mathrm{~g}$, 평균 재태

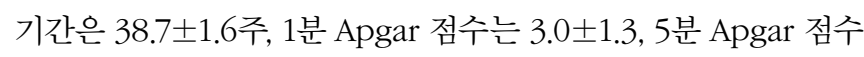
는 $5.4 \pm 1.7$ 였다. 대상아 49명 중 23명(46.9\%)에서 비정상 뇌 MRI 의 소견을 보였다. 주요 임상 소견들 중에 원외 출생과 경련이 비정 상 뇌 MRI 소견 군에서 정상 MRI 소견 군에 비해 통계적으로 의 미 있게 높았다 $(P<0.05)$ (Table 1).

\section{2. 비정상 뇌 $M R I$ 소견과 뇌 신경 발달}

주산기 가사로 인한 신생아 저산소 허혈 뇌병증 환자들에서 나 쁜 뇌신경 발달을 보인 환자는 비정상 뇌 MRI의 소견을 가진 환자 23 명 중 13 명(56.5\%)이었고, 이는 비정상 소견이 없는 환자의 4 명 (15.4\%) 보다 통계적으로 의미 있게 높았다 $(P<0.05)$ (Table 2). 단 순 분석에서 나쁜 뇌신경 발달과 통계적으로 의미 있게 관계가 있 었던 요인들인 경련, 5 분 Apgar 점수, 중증 저산소 허혈 뇌병증, 출 생 장소에서 심폐 소생술 미실시, 비정상 뇌 MRI 소견을 로지스 틱 회귀분석으로 보정하면 5분 Apgar 점수(odds ratio 0.4, 95\% confidence interval 0.2, 0.9. $P=0.03$ ), 심폐 소생술 미실시(odds ratio 29.0, 95\% confidence interval 2.7, 310.7, $P=0.005$ )와 비 정상 뇌 MRI 소견(odds ratio 9.7, 95\% confidence interval 1.4, $67.4, P=0.022$ )이 독립적으로 의미 있는 위험 요소였다(Table 3). 
Table 1. Comparison of Clinical Characteristics between Newborn Infants Postasphyxial Hypoxic-Ischemic Encephalopathy with and without Abnormal MRI Findings

\begin{tabular}{|c|c|c|c|}
\hline & Without abnormal MRI (n=26) & With abnormal MRI (n=23) & Total $(n=49)$ \\
\hline \multicolumn{4}{|l|}{ Neonatal characteristics } \\
\hline Birth weight (g) & $3,213.1 \pm 633.7$ & $3,124.1 \pm 674.3$ & $3,171.3 \pm 647.8$ \\
\hline Gestational age (wks) & $39.0 \pm 1.6$ & $38.4 \pm 1.6$ & $38.7 \pm 1.6$ \\
\hline Apgar score, $1 \mathrm{~min}$ & $3.1 \pm 1.4$ & $2.8 \pm 1.2$ & $3.0 \pm 1.3$ \\
\hline Apgar score, 5 min & $5.5 \pm 1.3$ & $5.4 \pm 1.0$ & $5.4 \pm 1.7$ \\
\hline Initial pH & $7.1 \pm 0.1$ & $7.1 \pm 0.2$ & $7.1 \pm 0.2$ \\
\hline Initial BE (mmol/L) & $13.6 \pm 6.5$ & $15.0 \pm 6$ & $14.2 \pm 6.5$ \\
\hline Male (\%) & $15(57.7)$ & $14(60.9)$ & $29(59.2)$ \\
\hline Twin (\%) & $2(7.7)$ & $1(4.3)$ & $3(6.1)$ \\
\hline IUGR (\%) & $3(11.5)$ & $1(4.3)$ & $4(8.2)$ \\
\hline Seizure* $(\%)$ & $6(23.1)$ & $13(56.5)$ & $19(38.8)$ \\
\hline Meconium aspiration (\%) & $8(30.8)$ & $2(8.7)$ & $10(20.4)$ \\
\hline RDS (\%) & $4(15.4)$ & $2(8.7)$ & $6(12.2)$ \\
\hline PPHN (\%) & $2(7.7)$ & $1(4.3)$ & $3(6.1)$ \\
\hline Hypoglycemia (\%) & $6(23.1)$ & $5(21.7)$ & $11(22.4)$ \\
\hline $\operatorname{ARF}(\%)$ & $1(3.8)$ & $1(4.3)$ & $2(4.1)$ \\
\hline Adrenal hemorrhage (\%) & $1(3.8)$ & $1(4.3)$ & $2(4.1)$ \\
\hline HIE, mild (\%) & $5(19.2)$ & $5(21.7)$ & $10(20.4)$ \\
\hline Moderate (\%) & $19(73.1)$ & $13(56.5)$ & $32(65.3)$ \\
\hline Severe (\%) & $2(7.7)$ & $5(21.7)$ & $7(14.3)$ \\
\hline \multicolumn{4}{|l|}{ Perinatal characteristics } \\
\hline Maternal age (yr) & $29.7 \pm 4.7$ & $31.1 \pm 4.3$ & $30.2 \pm 4.6$ \\
\hline Preeclamisa/eclampsia (\%) & $3(11.5)$ & $0(0.0)$ & $3(6.1)$ \\
\hline Diabetes (\%) & $1(3.8)$ & $1(4.3)$ & $2(4.1)$ \\
\hline Cesarean section $(\%)$ & $14(53.8)$ & $12(52.2)$ & $26(53.1)$ \\
\hline Breech (\%) & $0(0.0)$ & $1(4.3)$ & $1(2.0)$ \\
\hline Oligohydroamnios (\%) & $2(7.7)$ & $1(4.3)$ & $6(6.1)$ \\
\hline Outborn* $(\%)$ & $9(34.6)$ & $18(78.3)$ & $27(53.1)$ \\
\hline $\operatorname{PROM}(>18$ h) (\%) & $1(3.8)$ & $1(4.3)$ & $2(4.1)$ \\
\hline Fetal distress (\%) & $5(19.2)$ & $7(30.4)$ & $12(24.5)$ \\
\hline Meconium staining (\%) & $12(46.2)$ & $7(30.4)$ & $19(38.8)$ \\
\hline Sentinel events ${ }^{\dagger}(\%)$ & $20(76.9)$ & $16(69.6)$ & $36(73.5)$ \\
\hline No resuscitation at delivery (\%) & $3(11.5)$ & $5(21.7)$ & $8(16.3)$ \\
\hline \multicolumn{4}{|l|}{ Treatment } \\
\hline Inotropics use (\%) & $4(15.4)$ & $4(17.4)$ & $8(16.3)$ \\
\hline Mechanical ventilation (\%) & $19(73.1)$ & $16(69.6)$ & $35(71.4)$ \\
\hline Hypothermia therapy (\%) & $2(7.7)$ & $3(13.0)$ & $5(10.2)$ \\
\hline
\end{tabular}

Values are expressed as the mean \pm standard deviation or number of patients (\%).

${ }^{*} P<0.05$ between infants with and without abnormal MRI findings.

${ }^{\dagger}$ Sentinel events include placental abruption, cord accident, ruptured uterus, maternal cardiorespiratory arrest, any difficult prolonged labor to produce depressed birth with or without dystocia, and unexpected out-of-hospital birth without health care assistance and with history of asystole on arrival etc.

Abbreviations: BE, base excess; IUGR, intrauterine growth retardation; PROM, premature rupture of membrane; RDS, respiratory distress syndrome; PPHN, persistent pulmonary hypertension of newborn; ARF, acute renal failure; HIE, hypoxic-ischemic encephalopathy. 
Table 2. Comparison of Neurodevelopmental Outcomes between Newborn Infants with Postasphyxial Hypoxic-Ischemic Encephalopathy with and without Abnormal MRI Findings

\begin{tabular}{llc}
\hline & $\begin{array}{c}\text { Without } \\
\text { abnormal } \\
\text { MRI } \\
(\mathrm{n}=26)\end{array}$ & $\begin{array}{c}\text { With } \\
\text { abnormal } \\
\text { MRI } \\
(\mathrm{n}=23)\end{array}$ \\
\hline Developmental delay or cerebral palsy (\%) & $3(11.5)$ & $13(56.5)$ \\
SNHL (\%) & $1(3.8)$ & $0(0.0)$ \\
Died during follow up (\%) & $0(0.0)$ & $1(4.3)$ \\
Follow up loss (\%) & $5(19.2)$ & $2(8.7)$ \\
Poor neurodevelopmental outcomes* $(\%)$ & $4(15.4)$ & $13(56.5)$ \\
\hline
\end{tabular}

${ }^{*} P<0.05$ between infants with and without abnormal MRI findings. Poor neurodevelopmental outcome means one or more of DD, CP, and SNHL.

Abbreviation: SNHL, sensory neural hearing loss.

Table 3. Adjusted Odd Ratios for Poor Neurodevelopmental Outcomes in Infants with Postasphyxial Hypoxic-Ischemic Encephalopathy

\begin{tabular}{lrlc}
\hline & OR & $(95 \%$ CI $)$ & $P$-value \\
\hline Seizure & 1.2 & $(0.2,7.8)$ & 0.871 \\
Apgar score, five minute & 0.4 & $(0.2,0.9)$ & 0.030 \\
HIE stage, severe & 4.4 & $(0.4,52.9)$ & 0.248 \\
No resuscitation at delivery & 29.0 & $(2.7,310.7)$ & 0.005 \\
Abnormal MRI findings & 9.7 & $(1.4,67.4)$ & 0.022
\end{tabular}

Abbreviations: OR, odds ratio; CI, confidence interval; HIE, HypoxicIschemic Encephalopathy; MRI, magnetic resonance image.

\section{3. 뇌 손상 병변 형태에 따른 뇌신경 발달}

비정상 뇌 MRI 소견 중 뇌 손상 병변의 형태는 BGT 4명(17.4\%), WP 5명(21.7\%), EGI 3명(13.0\%), LPWM 4명(17.4\%), PAIS 2명 (8.7\%), PLIC 6명(26.1\%)이었다. 이들 중 BGT와 EGI는 100\%의 나쁜 뇌신경 발달을 보였으나, 뇌 백질 병변이 주인 WP와 LPWM 은 각각 $60.0 \%, 25.0 \%$ 로 BGT와 EGI에 비해 낮은 나쁜 뇌 신경 발달의 빈도를 보였다 $(P<0.05)$ (Table 4). PLIC는 6례 중 5례가 $\mathrm{BGT}$ 또는 EGI와 동반하여 있었고 6례 모두 100\% 나쁜 뇌신경 발달을 보였다. 그 외에 PAIS 2례도 100\% 나쁜 예후를 보였다.

\section{고찰}

뇌 MRI는 저산소 허혈 뇌병증에서 뇌손상을 평가하는데 널리 이용되는 검사로 뇌 손상의 위치와 심한 정도, 손상 형태를 파악 함으로써 손상의 시기와 원인을 추정하는 것뿐 아니라 신경 발달 의 예후를 예측하는 것에도 유용한 검사이다 ${ }^{22)}$.
Table 4. Neurodevelopmental Outcomes in Infants with Postasphyxial Hypoxic-Ischemic Encephalopathy According to the Brain Injury Patterns on MRI

\begin{tabular}{|c|c|c|}
\hline & $\begin{array}{c}\text { Abnormal } \\
\text { MRI } \\
\text { findings } \\
(n=23)\end{array}$ & $\begin{array}{c}\text { Poor } \\
\text { ND } \\
\text { outcomes } \\
(n=13)\end{array}$ \\
\hline Basal ganglia-thalamus pattern $(\%)^{*}$ & $4(17.4)$ & $4(100.0)$ \\
\hline Watershed predominant pattern of injury $(\%)^{*, \dagger}$ & $5(21.7)$ & $3(60.0)$ \\
\hline Extensive global injury $(\%)^{\dagger}$ & $3(13.0)$ & $3(100.0)$ \\
\hline $\begin{array}{l}\text { Lesions restricted to the periventricular white } \\
\text { matter }(\%)^{*, \dagger}\end{array}$ & $4(17.4)$ & $1(25.0)$ \\
\hline Perinatal arterial ischemic stroke (\%) & $2(8.7)$ & $2(100.0)$ \\
\hline Posterior limb of internal capsule (\%) & $6(26.1)$ & $6(100.0)$ \\
\hline
\end{tabular}

${ }^{*, \dagger} P<0.05$ between.

Abbreviations: MRI, magnetic resonance image; ND, neurodevelopment.

저산소 허혈 뇌병증의 뇌손상의 형태는 뇌의 저산소에 노출된 기간과 심각한 정도에 따라 다르며, 발달 중에 있는 뇌는 재태 연 령에 따라 손상 형태와 부위가 달라진다 ${ }^{24-28)}$. 과거, 영장류를 이용 한 동물 모델에서 주산기 가사에 의한 뇌 손상은 크게 질식 형태 에 따라 두 가지 형태로 발생하며, MRI 촬영이 보편화되면서 이에 관한 많은 연구들이 있어왔다 ${ }^{24,25,28)}$. 급성 완전 질식(acute near total asphyxia)에서는 주로 시상(thalamus)과 뇌간(brainstem) 의 겉질밑 핵(subcortical nuclei)의 손상이 주로 발생하고, 지속 성 부분 질식(prolonged partial asphyxia)에서는 방사상 대뇌 분수계(parasagittal cerebral watershed zone)의 손상이 주로 발 생되었다 ${ }^{28)}$. Pasternak과 Gorey ${ }^{27)}$ 는 급성 완전 질식에 의해 뇌 전 체 산소화가 우선 차단되면 뇌에서 가장 대사율(metabolic rate) 이 높은 시상, 기저 핵(basal ganglia), 뇌간(brainstem nuclei)이 먼저 손상되고, 부분 질식에서는 뇌 혈류가 대뇌 반구의 기저부 회 백질로 단락이 일어나 기저 핵과 뇌간은 보존되고 상대적으로 뇌 혈류가 차단되기 쉬운 뇌동맥 들의 경계 부위인 분수계(vascular watershed zones)를 중심으로 손상이 일어나 분수계 뇌 경색증 (watershed cerebral infarct) 또는 'white cerebrum'의 형태가 생기게 된다고 설명하고 있다. 또한, 발달 중인 뇌에서 특정 시기의 특정 부위에 따른 손상의 차이에 의해 미숙아의 경우 뇌실 주변부 백질(periventricular white matter) 손상이 흔하고 만삭아의 경 우 기저핵 및 시상 회백질 손상이 흔하다 ${ }^{26)}$.

주산기 가사 후 신경학적 예후를 평가하는데 있어 MRI 소견에 따라 신경학적 예후의 차이를 예측할 수 있음이 보고된 바 있으며 ${ }^{29-31)}$, MRI에서 보이는 뇌 손상의 형태에 따른 신경학적 예후의 차 이에 대해서도 몇몇 연구에서 밝혀진바 있다 ${ }^{12-16,23)}$. Roland 등 ${ }^{14)}$ 은 30개월에 시행한 평가에서 기저핵 및 시상의 손상이 운동 및 인지 기능 저하와 관련되어 있다고 보고하였고, Rutherford 등리 
은 PLIC의 신호변화는 운동 발달에 가장 중요한 예후 예측 인자로 활용될 수 있음을 보고하였다. 반면에 WP 형태는 주로 인지 기능 저하에 관련이 있었으며 이는 12 개월에는 나타나지 않을 수 있다 ${ }^{15)}$. Martinez-Biarge 등 ${ }^{16)}$ 에 따르면 선택적인 뇌 백질 또는 겉질의 손상은 BGT 손상에 비하여 뇌성 마비의 빈도를 훨씬 적게 보였으 나, 2세경에는 전반적 발달지연 및 언어, 행동 장애를 보였다고 보 고하고 있다. 또한 Steinman 등 ${ }^{12}$ 은 WP 형태를 보였던 아이에서 4세경에 더 낮은 지능지수를 보였다고 보고하였다.

본 연구에서도 저산소 허혈 뇌병증의 신생아에서 비정상 MRI 소견을 보였던 경우 보다 나쁜 신경학적 예후를 보였다. 뇌 MRI 소 견의 손상 형태에 따른 예후 차이는 BGT와 EGI 형태의 손상은 $100 \%$ 나쁜 뇌신경 발달 예후를 보였다. 또한 PLIC의 신호변화가 관찰된 경우에서도 나쁜 신경 발달 예후를 보였는데 이는 과거 연 구와 일치하는 결과였다 ${ }^{13,16,23)}$. LPWM과 WP 형태는 BGT와 EGI 에 비해 상대적으로 좋은 신경학적 예후를 보였으나, 본 연구에서 1 세에서 2세 사이에 신경학적 평가를 한 것을 고려할 때 추후 발달 지연 및 언어, 행동 장애에 대한 보다 장기적인 면밀한 추적 관찰 이 필요할 것으로 여겨 진다. 또한 van Kooij 등 ${ }^{32)}$ 은 뇌병증을 보였 던 신생아를 대상으로 한 연구에서 정상 및 국소적인 백질 손상의 MRI 소견을 보였어도 9-10세 경까지 추적 관찰 하였을 경우에 신 경 발달 장애가 생길 수 있는 것을 보고 한바 있어 정상 MRI 소견 을 보였더라도 정기적인 추적 관찰이 필요할 것으로 여겨졌다.

본 연구에서는 5분 Apgar 점수, 출생 장소에서 심폐소생술 미 실시, 비정상 MRI 소견이 신경 발달 장애와 관련된 위험인자였다. Apgar 점수는 만삭아에서 예후를 예측하는 지표로 사용되고 있 으며 5분 Apgar 점수가 0-3인 경우 신생아 사망의 중요한 예후 예 측 인자로 알려져 있다 ${ }^{33)}$. Mercuri 등 ${ }^{34)}$ 은 Apgar 점수와 MRI 소 견에 대한 연구에서 낮은 Apgar 점수가 BGT 손상과 연관이 있 다고 보고하고 있으며, 이는 낮은 Apgar 점수가 급성 저산소 허혈 성 손상과 관련이 있기 때문이다. 본 연구에서도 BGT 손상은 신 경 발달 장애와 높은 연관성을 보였으며, 이와 관련된 낮은 5 분 Apgar 점수가 주요 위험인자였다. 분만 장소에서 심폐소생술 미 실시는 출생 시 전신상태가 양호한 것을 의미하는 것이 아닌 출생 시 적절한 심폐소생술을 시행하지 못한 경우로 생각되며 이는 본 연구에서 개인 병원 출생 후 본원으로 전원 된 경우가 다수임을 고려할 때 $55.1 \%)$ 개인 병원 수준에서의 적절한 소생술의 시행 여 부가 신경 발달에 큰 영향을 미칠 수 있으며, 이에 대한 논의가 필 요할 것으로 생각된다. 또한, 가사를 유발할 수 있는 임상적 소견 들과 MRI에서 보이는 손상의 형태가 연관성이 있을 수 있으며 이 에 대한 추후 연구가 더 필요할 것으로 여겨졌다.

본 연구는 몇 가지 제한점을 가지고 있다. 첫째는 모든 대상아가 가사 후 같은 시간에 MRI를 촬영하지 못한 점이다. Rutherford 등 ${ }^{35)}$ 은 저산소성 뇌손상을 받은 아이들에서 7일까지는 뇌부종으로
인하여 정확한 소견을 보기 어려울 수 있음을 보고하였다. 본 연구 에서 MRI 촬영은 평균 8.6일에 이루어졌으나 7일 이전에 촬영된 아이들도 포함하고 있다. 둘째는 정상 MRI 소견을 보였던 대상아 중 4명(15.4\%)에서 신경 발달 장애를 보여 이 아이들에서 뇌 손상 이 과소평가되었을 가능성이 있다. 셋째로 본 연구에서는 주산기 가사로 인한 저산소성 허혈성 뇌증의 진단 기준으로 신생아 뇌증 의 증상이 있는 환자 들 중에서 하나 이상의 주산기 가사의 증거가 있는 경우로 하였는데, 주산기 가사의 증거들 중에 5 분 Apgar 점수 와 동맥혈 가스분석 $\mathrm{pH}$ 는 각각 7 미만과 $\mathrm{pH} 7.1$ 미만으로 하였다 ${ }^{17-20)}$. 이는 중증의 가사 $($ Apgar<3)와 제대 동맥혈 가스분석(<7.0) 을 사용한 다른 연구에 비해 다소 높은 기준이나 본 연구의 대상 환자들의 다수가 외부 출생 후 전원된 환자였기 때문에 제대 동맥 을 구할 수 없었고, 또한 Apgar 점수 기준도 가사를 의미할 수 있 는 보다 폭넓은 기준을 적용하였다. 넷째는 본 연구는 단일 기관에 서 시행한 연구로 대상아의 수가 작아 통계적 힘이 떨어지며 추후 다 기관에서 더 많은 환자를 대상으로 연구가 필요하겠다.

결론적으로 가사 후 신생아 저산소 허혈 뇌병증을 보인 신생아 에서 뇌 MRI 이상 소견은 나쁜 뇌 신경 발달과 의미 있는 관계가 있었으며, BGT, EGI 손상 형태와 PLIC 병변은 백질 손상이 주로 나타나는 WP와 PVWM에 비해 더 나쁜 신경 발달 예후를 보였다. 그 외에 PAIS 손상을 보인 2례에서도 100\% 나쁜 예후를 보였다.

\section{REFERENCES}

1) Badr Zahr LK, Purdy I. Brain injury in the infant: the old, the new, and the uncertain. J Perinat Neonatal Nurs 2006;20:16375.

2) Simon NP. Long-term neurodevelopmental outcome of asphyxiated newborns. Clin Perinatol 1999;26:767-78.

3) Sarnat HB, Sarnat MS. Neonatal encephalopathy following fetal distress. A clinical and electroencephalographic study. Arch Neurol 1976;33:696-705.

4) Mercuri E, Guzzetta A, Haataja L, Cowan F, Rutherford M, Counsell S, et al. Neonatal neurological examination in infants with hypoxic ischaemic encephalopathy: correlation with MRI findings. Neuropediatrics 1999;30:83-9.

5) van Laerhoven $H$, de Haan TR, Offringa $M$, Post $B$, van der Lee JH. Prognostic tests in term neonates with hypoxic-ischemic encephalopathy: a systematic review. Pediatrics 2013;131:8898.

6) van Wezel-Meijler G, Steggerda SJ, Leijser LM. Cranial ultrasonography in neonates: role and limitations. Semin Perinatol 2010;34:28-38.

7) Latchaw RE, Truwit CE. Imaging of perinatal hypoxic-ischemic brain injury. Semin Pediatr Neurol 1995;2:72-89. 
8) Swarte R, Lequin M, Cherian P, Zecic A, van Goudoever J, Govaert $P$. Imaging patterns of brain injury in term-birth asphyxia. Acta Paediatr 2009;98:586-92.

9) Barkovich AJ, Westmark K, Partridge C, Sola A, Ferriero DM. Perinatal asphyxia: MR findings in the first 10 days. AJNR Am J Neuroradiol 1995;16:427-38.

10) Barkovich AJ, Hajnal BL, Vigneron D, Sola A, Partridge JC, Allen F, et al. Prediction of neuromotor outcome in perinatal asphyxia: evaluation of MR scoring systems. AJNR Am J Neuroradiol 1998;19:143-9.

11) de Vries LS, Groenendaal F. Patterns of neonatal hypoxicischaemic brain injury. Neuroradiology 2010;52:555-66.

12) Steinman KJ, Gorno-Tempini ML, Glidden DV, Kramer JH, Miller SP, Barkovich AJ, et al. Neonatal watershed brain injury on magnetic resonance imaging correlates with verbal IQ at 4 years. Pediatrics 2009;123:1025-30.

13) Miller SP, Ramaswamy V, Michelson D, Barkovich AJ, Holshouser B, Wycliffe N, et al. Patterns of brain injury in term neonatal encephalopathy. J Pediatr 2005;146:453-60.

14) Roland EH, Poskitt K, Rodriguez E, Lupton BA, Hill A. Perinatal hypoxic-ischemic thalamic injury: clinical features and neuroimaging. Ann Neurol 1998;44:161-6.

15) Miller SP, Newton N, Ferriero DM, Partridge JC, Glidden DV, Barnwell A, et al. Predictors of 30-month outcome after perinatal depression: role of proton MRS and socioeconomic factors. Pediatr Res 2002;52:71-7.

16) Martinez-Biarge M, Bregant T, Wusthoff CJ, Chew AT, DiezSebastian J, Rutherford MA, et al. White matter and cortical injury in hypoxic-ischemic encephalopathy: antecedent factors and 2-year outcome. J Pediatr 2012;161:799-807.

17) Liauw L, van der Grond J, van den Berg-Huysmans AA, PalmMeinders IH, van Buchem MA, van Wezel-Meijler G. Hypoxicischemic encephalopathy: diagnostic value of conventional MR imaging pulse sequences in term-born neonates. Radio$\log 2$ 2008;247:204-12.

18) Duran R, Aladag N, Vatansever U, Sut N, Acunas B. The impact of Neonatal Resuscitation Program courses on mortality and morbidity of newborn infants with perinatal asphyxia. Brain Dev 2008;30:43-6.

19) Huang CC, Wang ST, Chang YC, Lin KP, Wu PL. Measurement of the urinary lactate:creatinine ratio for the early identification of newborn infants at risk for hypoxic-ischemic encephalopathy. N Engl J Med 1999;341:328-35.

20) Graham EM, Ruis KA, Hartman AL, Northington FJ, Fox HE. A systematic review of the role of intrapartum hypoxia-ischemia in the causation of neonatal encephalopathy. Am J Obstet Gynecol 2008;199:587-95.

21) Low JA, Lindsay BG, Derrick EJ. Threshold of metabolic acidosis associated with newborn complications. Am J Obstet Gyne- col 1997;177:1391-4.

22) Rutherford M, Biarge MM, Allsop J, Counsell S, Cowan F. MRI of perinatal brain injury. Pediatr Radiol 2010;40:819-33.

23) Rutherford MA, Pennock JM, Counsell SJ, Mercuri E, Cowan FM, Dubowitz LM, et al. Abnormal magnetic resonance signal in the internal capsule predicts poor neurodevelopmental outcome in infants with hypoxic-ischemic encephalopathy. Pediatrics 1998;102:323-8.

24) Okereafor A, Allsop J, Counsell SJ, Fitzpatrick J, Azzopardi D, Rutherford MA, et al. Patterns of brain injury in neonates exposed to perinatal sentinel events. Pediatrics 2008;121:906-14.

25) Triulzi F, Parazzini C, Righini A. Patterns of damage in the mature neonatal brain. Pediatr Radiol 2006;36:608-20.

26) McQuillen PS, Ferriero DM. Selective vulnerability in the developing central nervous system. Pediatr Neurol 2004;30:227-35.

27) Pasternak JF, Gorey MT. The syndrome of acute near-total intrauterine asphyxia in the term infant. Pediatr Neurol 1998;18: 391-8.

28) Myers RE. Two patterns of perinatal brain damage and their conditions of occurrence. Am J Obstet Gynecol 1972;112:24676.

29) Biagioni E, Mercuri E, Rutherford M, Cowan F, Azzopardi D, Frisone MF, et al. Combined use of electroencephalogram and magnetic resonance imaging in full-term neonates with acute encephalopathy. Pediatrics 2001;107:461-8.

30) Aida N, Nishimura G, Hachiya Y, Matsui K, Takeuchi M, Itani Y. MR imaging of perinatal brain damage: comparison of clinical outcome with initial and follow-up MR findings. AJNR Am J Neuroradiol 1998;19:1909-21.

31) Kuenzle C, Baenziger O, Martin E, Thun-Hohenstein L, Steinlin M, Good M, et al. Prognostic value of early MR imaging in term infants with severe perinatal asphyxia. Neuropediatrics 1994; 25:191-200.

32) van Kooij BJ, van Handel $M$, Nievelstein RA, Groenendaal $F$, Jongmans MJ, de Vries LS. Serial MRI and neurodevelopmental outcome in 9- to 10-year-old children with neonatal encephalopathy. J Pediatr 2010;157:221-7.

33) Casey BM, McIntire DD, Leveno KJ. The continuing value of the Apgar score for the assessment of newborn infants. N Engl J Med 2001;344:467-71.

34) Mercuri E, Rutherford M, Barnett A, Foglia C, Haataja L, Counsell S, et al. MRI lesions and infants with neonatal encephalopathy. Is the apgar score predictive? Neuropediatrics 2002; 33:150-6.

35) Rutherford MA, Pennock JM, Schwieso JE, Cowan FM, Dubowitz LM. Hypoxic ischaemic encephalopathy: early magnetic resonance imaging findings and their evolution. Neuropediatrics 1995;26:183-91. 